\title{
FUNDAMENTOS TEÓRICOS DE LA CULTURA DESDE LA ÓPTICA DE LAS ORGANIZACIONES ${ }^{1}$
}

\section{CULTURE'S THEORETICAL FOUNDATIONS FROM ORGANIZATIONS APPROACH}

\author{
Prince Luz Torres Salazar ${ }^{2}$ \& Enrique Melamed Varela ${ }^{3}$ \\ Universidad Simón Bolívar. Barranquilla-Colombia
}

RECIBIDO: Septiembre 06 de 2015

ACEPTADO: Noviembre 25 de 2015

DOI

\section{RESUMEN}

La cultura forma parte esencial del ser y es inherente a las estructuras organizadas, por ello este artículo de revisión se traza como objetivo explorar bajo un análisis crítico, los principales postulados teóricos referentes a la cultura, desde la perspectiva socioantropológica y como se ha adaptado el concepto a las organizaciones. Metodológicamente se soporta la revisión con un diseño de investigación descriptiva y enfoque cualitativo, de igual forma, la técnica de la revisión documental en plataformas de información científica, que representa la fuente de consulta y recuperación de las teorías y postulados pertinentes, analizados desde un contraste analítico y crítico. En el proceso de revisión se identificaron diferentes corrientes conceptuales que se han formado en referencia a la cultura y su adaptación en el panorama de las organizaciones, siendo su cultura resultado de la interacción de las personas en el contexto social y organizacional, ubicándose como un motor de identidad, permeando el sentido de pertenencia particular y colectivo y el sistema de creencias mediante diferentes dimensiones, niveles de análisis y elementos que surgen y modelan el capital cultural.

Palabras clave: Cultura, Cultura organizacional,Organizaciones, Sistema de creencias.

Códigos JEL: M14, D20, L20, D83.

\begin{abstract}
Culture is an essential part of human being and is inherent in organized structures, this review article aim to explore under a critical analysis, the main theoretical postulates concerning culture, from the perspective of socio-anthropological and how it has been adapted the concept to organizations. Methodologically revision is supported with a design of descriptive- qualitative research, in addition the document reviews platforms of scientific approach technique, which represents the source query and retrieval of relevant theories and postulates, analyzed from analytical and critical contrast. In the review process, different conceptual schools that have been formed in reference to culture and its adaptation in the organizations, being its culture result of the people interaction in the social and organizational context, ranking as an engine identity, permeating the individual and collective sense of belonging and belief system through different dimensions, levels of analysis and elements that emerge and shape the cultural capital.
\end{abstract}

Keywords: Culture, Organizational culture, Organizations, Belief system.

\section{Este artículo se puede referenciar}

Torres, P. \& Melamed, E. (2016). Fundamentos teóricos de la cultura desde la óptica de las organizaciones. En Desarrollo Gerencial Revista de la Facultad de Ciencias Económicas Administrativas y Contables de la Universidad Simón BolivarColombia, 8(1), 143-142.

1 Artículo de revisión en el marco de la tesis: Capital social y cultura en el emprendimiento de las Pymes. Un estudio de caso en la comunidad sirio-libanesa de Barranquilla para obtener el título de Doctor en Administración en la Universidad Autónoma de Querétaro, México.

$2 \mathrm{PhD}$ en Administración (c), Mg. en Administración de Empresas, Esp. en Gerencia de Recursos Humanos, Comunicadora Social y Periodista, Profesora de pregrado y posgrado, Asistente de Rectoría de la Universidad Simón Bolívar, Barranquilla, Colombia. ptorres5@unisimonbolivar. edu.co.

3 Administrador de Empresas, joven investigador del grupo de investigación Gestión Organizacional escalafonado en categoría A por Colciencias.emelamed@unisimon.edu.co 


\section{INTRODUCCIÓN}

Los estudios culturales en las organizaciones implican dimensionar las creencias y valores que comparten sus colaboradores, factores que modelan y determinan la identidad corporativa e influyen en el ambiente interno de trabajo; esta concepción tiene sus orígenes desde la teoría social que al convivir las personas en sociedad forman un sistema de costumbre, tradición y pensamiento propio de cada cultura que se materializa con aspectos como el lenguaje, la religión y el comportamiento en sociedad.

De igual forma, en el contexto de las organizaciones sucede un caso paralelo, los colaboradores que ingresan al sistema, configuran su propia cultura y esta se posiciona como un componentedel desarrollo y comportamiento organizacional, así como el modelo de creencias y valores compartidos entre los colaboradores del sistema, conocer este aspecto es relevante para procesos gerenciales tales como: gestión del cambio, fomento del trabajo en equipo, direccionamiento estratégico, administración por objetivos, entre otros.

En este sentido, desde el constructo del pensamiento administrativo se presentan las diferentes teorías y enfoques que se han formado en la disciplina de las organizaciones, así como el concepto cultural desde la perspectiva socio-antropológica y su extrapolación al contexto, como un factor crítico a tener en cuenta para la gestión y desarrollo del comportamiento humano. De esta forma, se identifica la teoría relevante que ha modelado la forma de concepción de la cultura en la dimensión organizacional y en las ciencias de la administración.

Como resultado se obtiene un recorrido a través de las diferentes dimensiones y enfoques de las organizaciones y también acerca de la cultura como parte de las sociedades que ha marcado y modelado el comportamiento humano, así mismo, estas al ser sistemas compuestos por individuos, dichos colaboradores crean y manifiestan una cultura que forma parte de su propia identidad y credo corporativo, elemento que representa una clave en la gestión gerencial y los diferentes procesos y actividades que se diseñan e implementan con la finalidad de establecer una correcta asociación y sinergia entre colaboradores y empresas.

\section{MÉTODO}

\section{Diseño}

La investigación se desarrolla bajo un diseño de investigación descriptivo que presenta como objetivo la recuperación de datos que faciliten retratar escenarios y características del objeto de estudio (Abreu, 2012). Igualmente, se contempla un enfoque cualitativo que propende por la naturaleza literaria de los da- 
tos, evitando la cuantificación; complementando, Aguirre y Jaramillo (2015) afirman que al interior de las investigaciones cualitativas se requiere de un adecuado grado de interpretación que complementa el diseño descriptivo, lo que permite generar material científico de mayor rigor.

\section{Instrumento}

Para la exploración de literatura que permite contar con el constructo teórico-conceptual referente a cultura y organizaciones, se acude a la técnica de revisión documental en fuentes secundarias científicas y plataformas de información fidedigna (Rojas, 2011), para el desarrollo del artículo se consultaron 60 fuentes que incluyen libros y artículos científicos relacionados con las líneasde investigación y como instrumento se establece una rúbrica de ideas y argumentos que fueron interpretados desde la perspectiva analítica y crítica respecto a la información secundaria recuperada.

\section{Procedimientos}

Para la construcción del marco de referencia se inicia con la definición de los conceptos principales: cultura y organizaciones, se revisan las teorías y enfoques desde las perspectivas: socio-antropológica y administrativa, respectivamente. Interpretadas las ideas referentes y configurados los fundamentos teóricos, se analiza la relación entre ambos aspectos y como se extrapola el acervo cultural a la dimensión corporativa a través del concepto de cultura organizacional, describiendo de esta forma el estado del arte del conocimiento en este componente de la disciplina de la administración y organizaciones.

\section{RESULTADOS}

\section{Marco general de las organizaciones}

Para Alonso, Ocegueda y Castro (2006) las organizaciones constituyen el objeto de estudio de la administración, la forma bajo la cual definen su modelo de actuación, también constituye uno de los principales ejes de estudio en la revisión e investigación administrativa y bajo este lineamiento se enmarca el planteamiento de la estructura organizacional, que de acuerdo a Mintzberg (1988) ha estado enmarcado bajo el enfoque de -una mejor forma- manifestado en las formas apropiadas y no apropiadas de diseñar una organización, no obstante, la diversa naturaleza de las organizaciones ha conllevado a que se fragüen modelos gerenciales exitosos y en ocasiones algunos fracasos, fruto de esta situación ha sido el cambio de paradigma de - a una mejor forma- a la noción del -todo depende de-, conocido en la teoría administrativa como la teoría de la contingencia. 
Dada la relativa turbulencia en el entorno de negocios, la estructura organizacional requiere contar un adecuado grado de flexibilidad que permita adaptarse a estos acelerados cambios, así como una debida capacidad de reacción y respuesta escenarios volátiles consecuencia de variaciones en el sistema (Mendoza, 2013). En este orden de ideas, se hace necesario conocer los diferentes elementos que configuran el sistema (ver figura 1), según Mintzberg (1988) estos inician comienzan desde los cimientos de la estructura conformada por los integrantes y su respectiva ejecución de las operaciones básicas, dichos miembros constituyen el denominado núcleo de las operaciones; en contrapartida al eje operativo, toda organización debe contar con miembros que ejerzan autoridad, vigilancia y control sobre las diversas actividades operativas, así se conforma el denominado ápice estratégico. Y finalmente, ligado al tamaño de la organización, se posiciona según el número de áreas funcionales de cada una, surge la línea intermedia que aglomera las divisiones necesarias para especializar las capacidades que permiten el correcto funcionamiento del sistema (David, 2003).

Por otra parte, la complejidad de las organizaciones también conlleva a la necesidad de un punto de vista diferente respecto a escenarios específicos, esta dimensión requiere generalmente de grupos del entorno que proporcionan el servicio de asesoría y/o consultoría en temáticas inherentes a la gerencia, este componente conforma la tecnoestructura y finalmente la estructura organizacional se apoya y complementa con procesos diferentes que se relacionan con su actividad principal, estas integran las unidades de apoyo administrativo (Mintzberg, 1988).

En última instancia, se ubica un sexto elemento denominado por Mintzberg (1988)como la ideología, cuya noción reúne el conjunto de tradiciones y creencias compartidas, esta ideología se posiciona como un factor diferencial y único de cada ente, representa un elemento generador de identidad y conducta en el contexto laboral, Smircich (1983) asevera que los ideales de las personas pueden ser alineados para alcanzar mejores resultados en el proceso de gestión.

Figura 1. Seis partes básicas de la organización

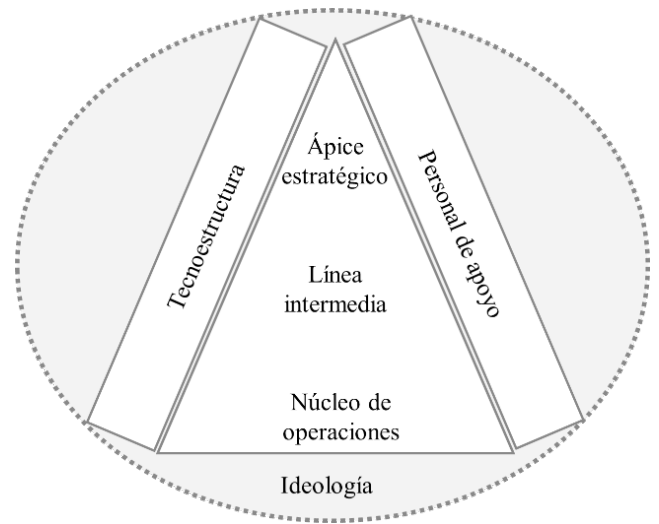

Fuente: Mintzberg (1988, p. 59) 
La propuesta de Mintzberg (2010) retrata claramente la radiografía de los elementos que conforman a las organizaciones y como estos componentes están presentes en su estructura, ya sea en el ámbito físico o tácito forman parte del sistema y contribuyen al funcionamiento y desarrollo de los recursos y capacidades de la gestión organizacional. De esta forma se configura la categorización de niveles jerárquicos y unidades copartícipes que soportan el desarrollo de las políticas y estrategias que permiten el logro de los objetivos trazados por la gerencia, así como la pertinente construcción colectiva que coadyuva a la existencia del sistema de organización interna.

\section{Enfoques organizacionales}

Los diversos estudios en las ciencias administrativas han adoptado diferentes perspectivas a través del tiempo, realizar un análisis exhaustivo de los diferentes enfoques sobre la investigación teórica en la gestión de organizaciones es una actividad compleja, agregado a ello suele confundirse la temática con los modelos gerenciales, si bien ambas temáticas son complementarias son elementalmente distintas (Zalpa, 2002).

\section{- Enfoque clásico}

La escuela clásica se orienta a la concepción de la estructura e infraestructura de la organización como el engranaje de un sistema rígido, estandarizado y mecanicista (Morgan, 1997; Simon, 2013), este principio se fundamenta en una filosofía de gestión basado en las decisiones racionales y eficientes, a pesar de que el modelo clásico ha mermado su vigencia a través del tiempo, algunas organizaciones han fortalecido su capacidad competitiva bajo las premisas del modelo clásico, incluso fraguando técnicas de gestión mundialmente conocidas por sus efectivos resultados, ejemplos como: la gestión de la calidad total, control estadístico de procesos, inventarios justo a tiempo, entre otros (Zalpa, 2002).

\section{- Enfoque de las relaciones humanas}

El enfoque de las relaciones humanas marcó en la teoría administrativa el hito del posicionamiento de las personas en la organización como miembros de suma importancia para los procesos administrativos, esta perspectiva tuvo sus inicios con los estudios de Elton Mayo (2004) en la fábrica de Hawthorne, la vertiente de las relaciones humanas se complementa con los aportes de McGregor(2006) con su aporte ideológico fundado en la forma en la que los administradores gerencian las organizaciones bajo sus ideas propias que poseen acerca de sus colaboradores, agregado a ello los principios base del enfoque humanístico, lo constituyen la idea que estudiar a la organizaciones implica estudiar a sus miembros, motivaciones, relaciones y normas formales e informales que surgen de la convivencia, tipos de liderazgo, entre otros. De igual forma, la gerencia debe propender por el alineamiento adecuado de los objetivos corporativos con los individuales, de esta forma las organizaciones alcanzarán un adecuado crecimiento y desarrollo en la misma medida que sus miembros (Zalpa, 2002). 


\section{- Enfoque estructuralista}

Mouzelis (1973) afirma que la escuela estructuralista busca la integración de las escuelas clásica y de relaciones humanas, partiendo del supuesto que las organizaciones son sistemas reguladores del comportamiento humano para el logro de los objetivos y metas, así como requieren de la debida departamentalización que facilite la distribución de funciones y responsabilidades en unidades específicas que conjuntamente aportan la actividad económica principal del sistema. La escuela estructuralista propende por la organización matricial que tiene en cuenta la diversificación de variables imprescindibles para la consecución de las metas, a la par que se busca la diferenciación e integración de las áreas funcionales, como instrumento básico de trabajo los organigramas (Zalpa, 2002).

\section{- Enfoque sistémico}

El enfoque sistémico se fundamenta en concebir a la organización como un sistema de información, el marco referencial para soportar las decisiones lo constituye la información debidamente soportada en análisis cuantitativo y confiable, si dicha información recorre de forma correcta por los canales de comunicación interna, esta perfila en una mejor condición para determinar sus objetivos y las estrategias pertinentes para lograrlos (Zalpa, 2002).El mayor aporte al enfoque sistémico de las organizaciones, lo constituye la teoría general de los sistemas desarrollada por Bertalanffy (2006), este último define un sistema como un conjunto complejo de elementos organizados que interactúan continuamente, bajo esta premisa también existen una serie de modelos, normas y principios que rigen el desenvolvimiento normal de los sistemas y la forma símil de operación de las organizaciones (Athehortúa, Bustamante y Valencia, 2008).

\section{- Teoría de la contingencia estructural}

El enfoque contingente parte del paradigma en el cual las organizaciones deben adaptarse al entorno, las organizaciones en este sentido no son entes estables, sino que deben adaptar a la modalidad de percepción del entorno, dicha percepción conjuga los factores contingentes de las organizaciones, que acuerdo a Donaldson (1996) algunos factores determinísticos en el modelo de negocio de las organizaciones son: la estrategia corporativa, tamaño, tecnología, claridad y complejidad de los objetivos organizacionales, entre otros.

\section{Generalidades de la cultura}

La cultura es inherente a cualquier sociedad, evocando la definición antropológica de Morín (1999), el hombre es pues un ser plenamente biológico, pero si no dispusiera plenamente de la cultura sería un primate del más bajo rango. La cultura acumula en sí lo que se conserva, transmite, aprende; ella comporta normas y principios de adquisición. La mente humana es un surgimiento que nace y se afirma en la relación 
cerebro-cultura. Complementando lo anterior, los autores a continuaciónsugieren una definición para la cultura como un conjunto de representaciones simbólicas y prácticas en contextos estructurales que tienen los dueños de las organizaciones.

Allaire y Firsirotu (1984) exponen la cultura como un sistema ideacional, cambiando la manera de abordar las investigaciones dentro de este campo. La cultura se construye a partir de los conceptos del mundo y con productos simbólicos, es un contexto dinámico cargado de símbolos, conocimientos funcionalistas o una estructura mental profunda y subconsciente. Este concepto además es compartido por Wallace (1970), que ve la cultura como un sistema de cogniciones que permiten a los empleados predecir mutuamente sus comportamientos y así multiplicarlo en la sociedad, a pesar de las motivaciones y metas tan divergentes. Este concepto va en contra de la teoría de las metas comunes, de las creencias y significados colectivos, es el pequeño número de cogniciones de las cuales se vale el individuo para predecir el comportamiento futuro de los demás. La cultura no es un elemento estático, por el contrario, el dinamismo está tácito en él, esta es una materia viva que es llevada por cada empleado y transformada a su vez durante el proceso de decodificación de los acontecimientos organizacionales.

Así mismo, Fleury (2002) identificó cinco rasgos que caracterizan cualquier cultura:

- Es un fenómeno colectivo, la cultura está estrechamente relacionada con un grupo humano la cual es una estructura formal y profunda; está en contacto con los diferentes eventos (ritos, ceremonias, intercambios, fiestas, entre otros) donde se relaciona.

- Precede de una actividad simbólica omnipresente, cualquier actividad cultural es una producción de sentido, esta actividad simbólica caracteriza a la cultura como un fenómeno puramente humano.

- Se incluye en la transmisión, la cultura es el ámbito del aprendizaje, la imitación, la incorporación de la repetición y la interacción. Es a través de la cultura que se organiza la continuidad del grupo.

- Se trata de un informe dentro de un exterior, siempre es una relación dialéctica con el exterior: la naturaleza o de otras personas.

- Se caracteriza por su coherencia interna, parece que está organizada y es un sistema que tiene forma; pero no es rígida. La cultura está hecha de correspondencia suave, interpretaciones y adaptaciones.

De igual forma, Laplantine (1993) define que la cultura:

"Es lo que distingue a la sociedad humana de la sociedad animal, es que de ninguna manera hay transmisión de información, división del trabajo, especialización jerárquica de tareas, pues esta forma de comunicación específicamente cultural es el proceso de intercambio de signos y símbolos.” (p. 117) 
Por otra parte, Hofstede (1980) describe unas dimensiones culturales y sus efectos en una sociedad, a través de los valores de sus miembros, y cómo estos valores se traducen luego en conductas, utilizando una estructura derivada del análisis factorial. Esta teoría a su vez ha sido pertinente en varios campos de estudio como los paradigmas para la investigación, en la psicología intercultural, gestión internacional, y la comunicación intercultural. Hofstede (1980) desarrolló un modelo original como resultado del uso de análisis factorial para examinar los resultados de una encuesta mundial de valores de los empleados de la International Business Machines (IBM) en la década de los años 60 y 70. La teoría fue una de las primeras que podía ser cuantificada y que podía ser utilizada para explicar las diferencias observadas entre las culturas. La teoría original propuso cuatro dimensiones en las que los valores culturales pueden ser analizados:

- El individualismo-colectivismo: El grado en que los individuos se integran en grupos. En las sociedades individualistas, el acento está puesto en los logros personales y los derechos individuales. Se espera que la gente se valga por sí mismos o de su familia inmediata, y que escoja sus propias conexiones. Por el contrario, en las sociedades colectivistas, los individuos actúan predominantemente como miembros de un grupo u organización permanente y coherente.

- Evitación de la incertidumbre: La tolerancia de una sociedad para la incertidumbre y la ambigüedad. Este refleja el grado en que los miembros de la sociedad hacen frente a la ansiedad, reduciendo al mínimo la incertidumbre, las personas en las culturas con alta evitación de la incertidumbre tienden a ser más emocionales. Por el contrario, los cultivos de evitación bajo incertidumbre aceptan y se sienten cómodos en situaciones no estructuradas o entornos cambiantes y tratan de tener tan pocas reglas como sea posible.

- El poder de la distancia, el poder es el grado en que los miembros menos poderosos de las organizaciones e instituciones (como la familia) deben aceptar y esperan para que no sea distribuido de manera desigual. Hay culturas que avalan la baja distancia y esperan y aceptan las relaciones de poder que son más consultivas o democráticas.

- La masculinidad-feminidad (orientación a la tarea frente a la orientación a la persona): La distribución de los roles emocionales entre los géneros. Los valores de culturas masculinas son: la competitividad, la asertividad, el materialismo, la ambición y el poder, mientras que los cultivos femeninos dan más valor a las relaciones y la calidad de vida.

Hofstede (1980) agrega una quinta dimensión, la orientación a largo plazo, para cubrir aspectos de los valores que no se analizan en el paradigma inicial. 30 años después el autor añadió una sexta dimensión, la indulgencia frente a la moderación, como resultado del análisis de los datos de la encuesta mundial de valores.

Triandis y Suh (2002) exponen que la cultura no es de ninguna manera un asunto sencillo, una de las 
posibles maneras de pensar la cultura es creyendo que "la cultura es a la sociedad como la memoria es a los individuos". Esto incluye lo que se trabaja desde la experiencia de la sociedad y que vale la pena transmitir a las nuevas generaciones. Los elementos de la cultura son procedimientos operacionales compartidos de manera estándar, suposiciones, herramientas, normas, valores, hábitos de acuerdo a lo que se vive en el medio ambiente y que son de interés para el análisis psicológico.

Para Triandis (2004) las personas que se desarrollan en culturas individualistas como las del Norte y el Occidente Europeo, así como las de Norte América, son más probables a que utilicen un discurso desde el yo (ejemplo: yo estoy ocupado o yo soy agradable); mientras las personas de culturas colectivistas, como aquellas de Asia, África y Suramérica, tienden a mostrar más elementos desde el yo colectivo (ejemplo: Mi familia piensa que yo paso muy ocupado o mis colegas creen que soy agradable).

\section{- Nivel de análisis de la cultura individualista y colectivista}

La cultura individualista es el polo de la cultura colectivista. En esta cultura vertical, como es el caso de las organizaciones de Norteamérica, la competitividad es alta y se trabaja para ser el primero y poder lograr alcanzar la jerarquía. En la cultural individual horizontal (Australia y Suecia) la diferenciación jerárquica está enfatizada en la autosuficiencia, la independencia del otro y la singularidad.

Triandis y Suh (2002) proponen que el colectivismo es alto en culturas que son simples y cerradas. En la cultura colectivista, la gente es interdependiente en sus grupos cercanos (familia, tribu, país), dan prioridad a los objetivos grupales y definen sus comportamientos principalmente sobre la base de las normas del grupo de manera comunitaria.

Hay muchas clases de cultura colectivista. Una importante distinción es la hecha entre la cultura vertical (India) y la horizontal (Israel). Las culturas verticales son tradicionalistas y enfatizan en la cohesión de los grupos cercanos (in-groups), respeto por las normas, y las directivas de autoridad. Por ejemplo, el colectivismo vertical está correlacionado con la tendencia de ser sumiso ante la autoridad y de aprobar el convencionalismo, mientras la cultura colectivista horizontal enfatiza en la empatía, sociabilidad y la cooperación.

Gabriel y Gardner (1999) encontraron otra variación de colectivismo entre los géneros. De acuerdo a la investigación, la colectividad masculina es derivada de la pertenencia a un grupo (yo soy americano); mientras que la colectividad femenina es derivada de relaciones específicas (yo soy la mejor amiga de Amanda). Un rasgo que define a las personas de la cultura colectivista es su notable preocupación por las relaciones. Por ejemplo, la cultura colectivista en situaciones de conflicto está principalmente preocupada con mantener las relaciones con los otros, mientras que los individualistas lo están por alcanzar la justicia. 
Entonces, el colectivismo prefiere métodos de resolución de conflicto que no destruyan las relaciones y los individualistas en cambio están dispuestos a ir a los tribunales a resolver sus conflictos.

Una importante contribución desde el trabajo realizado por Hofstede (1980) fue el énfasis en la distinción entre el nivel de individualismo y colectivismo y cómo éstos se oponían. Pero cuando un trabajo profundo sobre estos niveles de análisis fue realizado, el individualismo fue clasificado dentro de varias facetas (como la distancia de los grupos de trabajo, hedonismo y rivalidad) y el colectivismo a su vez clasificado en muchos factores como la integridad familiar y sociabilidad. Estos factores entonces no fueron más opuestos, sino que podían ser correlacionados, así de esta manera una persona puede tener altamente desarrollado en ambos niveles. Por ejemplo, estudios han demostrado que la gente que crece en una cultura colectivista y que luego vive en una cultura individualista por muchos años, tuvieron altos rasgos de ambos niveles. Otros estudios sugieren que esta misma gente fue más adaptable y que pudieron manejar las adversidades con más éxito (Triandis, 2004).

\section{- Capital cultural}

La arquitectura de la estructura social, correlaciona al ser humano y su interacción con las diferentes instituciones sociales como: la familia, la escuela, la iglesia, entre otras; esta continua y necesaria relación construye una visión particular en los individuos y colectivamente una perspectiva compartida implícita en su capital cultural; este concepto de acuerdo a Bourdieu (1979) hace referencia a los diferentes atributos adscritos y/o adquiridos por el ser humano a través de la convivencia social, ubicándose como la principal fuente de capital cultural a la familia. Este capital influye fuertemente en las capacidades humanas, dada la relación entre las condiciones sociales y el desempeño. Inicialmente el concepto de capital cultural presenta su universo de estudio en el ámbito educativo, específicamente en el aspecto del rendimiento académico de los estudiantes correlacionado con sus condiciones de vida.

De acuerdo a Jiménez (1997) el espacio social articula dos vertientes: el capital económico como medio de gestión y construcción de la infraestructura social y el capital cultural manifestado cómo los elementos innatos de los valores y la ética, producto de la educación familiar.

Agregado a ello, Herrera, Inglehart, Baker y García (2002) manifiestan que el capital cultural y el desarrollo económico están íntimamente ligados, esta relación si bien no es de forma directa, se presenta a través de las organizaciones dada la influencia del capital cultural en el recurso humano que forma parte de la estructura organizacional. Bourdieu (1979) agrega que la aptitud de los individuos más allá de la formación y calificación producto de las inversiones económicas en el estudio, también es producto de la inversión en tiempo y capital cultural, Maas (2006) afirma que el capital cultural también se traduce en ganancias y bienes de tipo simbólico, es decir, aquello que no se consigue directamente con dinero. 
Además, Bourdieu (1979) manifiesta que el capital cultural puede existir en tres modalidades, en primera instancia el estado incorporado hace relación a las propiedades innatas en el ser humano, el estado objetivado que representa la materialización de ideas en bienes tangibles como libros, pinturas, monumentos, esculturas, entre otras y finalmente, el estado institucionalizado donde trasciende a títulos que equivalen a estatus institucionales, este reconocimiento confiere la capacidad de establecer la convertibilidad entre capital económico y capital cultural.

\section{- Cultura y organizaciones}

La cultura de un grupo puede ser definida como un patrón de criterios básicos compartidos, aprendido como solución a los problemas de adaptación externa e integración interna, que hayan dado resultados positivos para ser considerados como válidos, por consiguiente, aprendidos por los nuevos miembros, como la manera correcta de percibir, pensar y sentir en relación a esos problemas (Schein, 2010).

Por su parte, Smircich (1983) sugiere dos sentidos para el concepto de cultura, una vista como variable y la otra como una metáfora; desde la definición como variable, tiene sentido desde lo que la organización es y posee, viéndose como una variable externa (cultura de un país) o interna (cultura desde la organización). Como una metáfora, la cultura se concibe relacionada integralmente con los aspectos antropológicos, aquellos intangibles y de difícil cambio.

La cultura al formar parte de las organizaciones se dimensiona y relaciona con otros aspectos propios de la arquitectura organizacional, como el liderazgo gran incidencia de la identidad corporativa influye en la transformación o transacción de los lideres con el desarrollo de sus actividades (Da Silva, Kishore, Germano, Lopesy Medeiros, 2013). En las organizaciones es normal tratar la temática de la cultura, pues este ha constituido el objeto de estudio de múltiples estudiosos de la materia y es por ello, que el factor cultural e ideológico de las organizaciones requiere una gestión coherente y sistemática en cualquier tipo de organización (Lessem, 1992).

Se puede afirmar que la cultura no es más que un sistema de elementos, productos, ideas, creencias, legislaciones, entre otras. Es un gran sistema cuyos engranajes están clasificados en materiales, humanísticos y espirituales. Y es mediante dicho sistema que el ser humano hace frente a los fenómenos de la realidad y desarrolla soluciones concretas a las adversidades que conlleva el hecho de existir, en este orden de ideas la cultura presenta tres componentes: lo tecnológico que implica la realidad física, es decir las herramientas, elementos prácticos y recursos que interactúan con el ser humano en su diario vivir, lo sociológico relacionado con la convivencia del hombre en sociedad y las diversas consecuencias que acarrea la interacción con otros y finalmente el aspecto ideológico que abarca el sistema general de costumbres, conductas y creencias del ser humano en lo que concierne a lo ético, moral y religioso (Lessem, 1992). 
A nivel organizacional la concepción de cultura no es muy distinta, cada organización cuenta con su identidad corporativa y un sistema de creencias así como0 valores compartidos que influyen en la modalidad de actuación de cada miembro de la organización, elementalmente la cultura en la organización agrupa conceptos más puntuales que integrados coadyuvan a la generación del modelo cultural de la organización. Los principios básicos de la compañía constituyen los aspectos fundamentales que orientan el ¿qué se hace? y ¿hacia a donde se va?, enmarcan la actividad de la organización a fin de transmitir a sus participantes y grupos de interés un marco de referencia respecto a los principios que orientan su funcionamiento, el credo de los empleados constituye el sistema armónico de creencias y nociones presentes en los diferentes miembros de la organización, generalmente determinan las actitudes frente las diversas situaciones fruto de las labores habituales y los valores corporativos que conforman las bases axiológicas de la organización delimitando una actuación ética en la actividad empresarial (Zalpa, 2002).

Ahora, las organizaciones dada su continua interacción con el entorno están en la necesidad de adaptar sus diferentes elementos y componentes a las condiciones que surjan en los diferentes momentos en el tiempo, es donde se origina el enfoque contingente de las organizaciones (Donaldson, 1996), ante este escenario, Kotter y Heskett (1995) aluden al enfoque adaptativo de la cultura en sintonía con los demás componentes de la organización, de esta forma se logra una adecuada posición proactiva y de anticipación frente los cambios del entorno, propiciando a la organización la posibilidad de tomar decisiones oportunas con el fin de minimizar el riesgo y en el largo plazo significativos niveles de rentabilidad.

En este orden de ideas Kilman, Saxtony Serpa (1985) manifiestan que las culturas adaptables están relacionadas con la asunción de un pensamiento que coadyuva a una filosofía de proactividad, en sinergia con la vocación de asumir riesgos y la fe en los cambios como respuesta a las exigencias del entorno, este paradigma se traduce desde el ente propio de la organización hasta los individuos que la conforman, de igual forma coexiste el empoderamiento, la motivación y el sentido de la confianza para afrontar los diferentes retos que emerjan, esta filosofía se transmite y trasciende a una visión compartida implícita en las organizaciones.

Berger (1991) tiene una aproximación práctica y argumenta que el emprendedor es del ámbito local y que repite comportamientos aprendidos desde su nacimiento, en contraposición a la vista de autores como Gerschenkron (1974) y Hirschman (1958) de la línea económica, quienes describen que, si las condiciones económicas del país no son favorables, el emprendimiento se verá estancado. Berger (1991) explica a través de la analogía del sistema eléctrico que la cultura es el conductor y el emprendedor es el catalizador. Vale la pena aclarar que, entre los científicos sociales comprometidos con un análisis cultural del fenómeno emprendedor, los psicólogos sin duda sobresalen, aunque sólo sea para demostrar la necesidad de separar los factores psicológicos de la iniciativa empresarial de los de la cultura.

McClelland (citado por Berger, 1991) ha sido capaz de identificar los factores psicológicos ceñidos a la 
iniciativa empresarial, estipulando que los diferentes individuos poseen unidad y la motivación en diferentes grados. Muy probablemente estas diferencias son el resultado de un complejo proceso de socialización en el que psicológica y genéticamente, factores como la familia y la clase social interactúan en una variedad de forma, pero es importante tener en cuenta que se requiere de condiciones culturales para dar forma y sentido a los potenciales individuales.

\section{Orígenes y desarrollo del concepto de cultura organizacional y su relación con la cultura local}

Giddens (citado por Contreras, López y Ríos, 2011) define la cultura organizacional como:

"Valores, normas y bienes materiales característicos de un determinado grupo. Al igual que el concepto de sociedad, el de la cultura se usa con profusión en sociología, así como en otras ciencias sociales. La cultura es uno de los rasgos más característicos de las asociaciones sociales humanas" (p. 8).

En el mismo sentido, Montaño (2000) describe la cultura organizacional desde una propuesta renovada del modelo burocrático que busca identificar las cualidades de los trabajadores dentro de la organización, para motivar en ellos la competitividad. El autor explica que la cultura se ha estudiado históricamente en tres dimensiones: La cultura obrera, la cultura nacional y la cultura organizacional. Esta última no fue estudiada ni tenida en cuenta por muchos sociólogos, quienes fueron los primeros en hablar del tema de cultura, a pesar de la diversidad en el contexto organizacional del que eran parte las empresas estadounidenses del siglo XIX luego de la migración europea.

De igual forma, Schein (2010) define la cultura organizacional como la forma en que la empresa ha aprendido a manejar su ambiente, una mezcla compleja de supuestos, conductas, relatos, mitos, metáforas y otras ideas que definen lo que significa trabajar en una organización particular. Los autores además exponen, que la cultura en una organización tiene su origen en aspectos como su historia y su entorno; y se da a conocer a través del lenguaje, la comunicación, el sistema de producción de bienes materiales, sociales e inmateriales, las relaciones interpersonales, el liderazgo y las subculturas (Zapata y Rodríguez, 2008). Lo señalado coincide con Davis (1993), quien plantea que las organizaciones, como las huellas dactilares, son siempre únicas. El baluarte de la cultura organizacional se puede inferir como el grado de presión que ejerce sobre los integrantes de la organización y sobre sus comportamientos. Para analizar la cultura, Morcillo (2007) por ejemplo, señala al liderazgo, los valores, la ética, la sociabilidad y la solidaridad, el éxito, las ventajas competitivas y la innovación; frente a este último elemento, De la Hoz y Forero (2013) manifiestan que para su gestión es necesario el desarrollo de un ambiente dinamizador de las habilidades humanas que permitan ubicar el pensamiento creativo como parte de la cultura de las organizaciones.

Bases teóricas que complementan los referentes de cultura organizacional, es el enfoque desarrollado 
por North (1990) respecto a la influencia del entorno, en la acción de las personas de fijarse objetivos y las respectivas estrategias para alcanzarlos; mientras que la teoría de los recursos y capacidades dictamina que la cultura funciona como generadora de elementos diferenciadores que fortalecen su capacidad competitiva (Barney, 1991; Cuervo, 1993).

La cultura es así un medio que podría ser administrado para mejorar el desempeño y el logro de los objetivos (Smircich, 1983), la dirección de una organización puede entonces formular una estrategia interna para aumentar la identificación y la cohesión de los integrantes alrededor de los valores claves para la estrategia externa, de tal forma que con las acciones pertinentes coadyuve al mejoramiento continuo del desempeño organizacional y alcanzar los objetivos.

Estrada y Sánchez (2009) exponen que a nivel global se han desarrollado diferentes herramientas para la medición del desempeño de las empresas: financiero, operativo y de eficacia; algunas son objetivas/ cuantitativas, extraídas de cifras o datos, de sistemas contables y presupuestales o del sistema del Cuadro de Mando Integral (CMI); algunas son subjetivas/cualitativas, es decir, se obtienen explorando la percepción o los puntos de vista de actores involucrados en los procesos de la empresa y, en algunos casos, de observadores externos. Hasta el momento no existe acuerdo respecto de un indicador generalizable para medir el rendimiento.

Méndez (2006) define la cultura como una conciencia colectiva que se expresa en el sistema de significados compartidos por los miembros de la organización que los identifica y diferencia de otros institucionalizando y estandarizando sus conductas sociales. Tales significados y comportamientos son determinados por el concepto que el líder de la organización tiene sobre el hombre, la estructura, el sistema cultural, y el clima de la organización, así como por la interrelación y mutua influencia que existe entre estos.

Con lo anterior se infiere que el sistemas de significados compartidos por los miembros de de la organización son aquellos que identifican todas la caracteristicas, patrones y comportamientos dentro de un entorno laboral, la cual varia según las politicas de la organización y su funcionamiento dentro de ella, dentro de cada organización se presentan modelos estipulados que los empleados deben seguir para cumplir los procesos de productividad y eficiencia que forman la imagen de un a empresa,cuyos patrones dados estan para cumplir con los valores corporativos de la empresa, asi mismo el clima organizacional influyen en la cultura de cada organización dando aspectos positivos o negativoss al comportamiento de las dentro de ellas.

Así mismo se destaca que "los componentes íntegramente relacionados, a la estructura y la cultura son los de gestión humana, comunicación e información, estrategia, innovación y conocimiento y estructura y cultura organizacional entre sí” (Deninson, citado por Uribe, 2007, p. 75). 
Respecto a la forma de la cultura organizacional, el modelo propuesto por Cameron y Quinn (2011) identifica cuatro tipos de cultura: de clan, adhocrática, jerárquica y de mercado (ver tabla 1). La primera cultura se enfoca en el desarrollo humano, el trabajo en equipo, y el compromiso con la organización, por otra parte, la cultura jerárquica, la cual tiene una orientación al interior de la empresa busca la estabilidad y el control dentro de la misma, se basa en valores como eficiencia, orientación al cumplimiento de los procesos y las reglas dentro de las empresas.

Por otra parte, la cultura adhocrática, es la que valora primordialmente la flexibilidad, y con orientación externa, las empresas que las tienen son las empresas que buscan tener un liderazgo en el mercado y operan en situaciones de contingencia permanente. También está la cultura del mercado, la cual pone énfasis en lo externo para aumentar la competitividad empresarial y el aumento de su productividad (Ruiz y Naranjo, 2012).

Tabla 1. Tipos de culturas en las empresas

\begin{tabular}{l} 
CLAN \\
\hline Características: Valores y objetivos com- \\
partidos, cohesión, implicación de los \\
empleados, compromiso, sentido del "no- \\
sotros", equipos de trabajo, consenso. \\
- Tarea de gestión: potenciar a los emplea- \\
dos y facilitar el compromiso, la partici- \\
pación y la lealtad.
\end{tabular}

- Espacio de trabajo: amistoso, en el que las personas comparten mucho de sí mismos.

- Líderes: mentores, figuras paternas.

- Meta a largo plazo: beneficio del desarrollo individual con una moral y cohesión alta.

\section{ADHOCRÁTICA}

- Características: Adaptabilidad, flexibilidad, creatividad, convivencia con la incertidumbre y la ambigüedad de la información, ausencia de poder centralizado y de cadenas de mando bien establecidas, énfasis en la individualidad, el riesgo y la anticipación.

- Tarea de gestión: estimular el riesgo, el conocimiento y la creatividad para estar siempre adelante. Crear una visión de futuro, gestionar el caos, disciplinar la imaginación.

- Espacio de trabajo: dinámico, emprendedor y creativo.

- Líderes: visionarios, innovadores, orientados al riesgo.

- Meta a largo plazo: crecimiento rápido, adquisición de nuevos recursos, producir servicios y productos únicos y originales.

\section{JERÁRQUICA}

- Características: reglas formales, especialización, meritocracia, jerarquía, impersonalidad, mecanismos de responsabilidad, control, los procedimientos rigen lo que las personas hacen.

- Tarea de gestión: coordinación y aplicación de los procedimientos.

- Espacio de trabajo: formalizado y estructurado.

- Líderes: buenos coordinadores y organizadores.

- Meta a largo plazo: estabilidad, previsibilidad y eficiencia.

\section{MERCADO}

- Características: orientación hacia el exterior, el control viene de los mecanismos del mercado, énfasis en las transacciones (intercambio, ofertas, contratos) con agentes externos para crear ventajas competitivas. La competitividad y productividad son los valores clave. El entorno es hostil y los clientes exigentes.

- Tarea de gestión: dirección por objetivos.

- Espacio de trabajo: orientación a resultados.

- Líderes: productores exigentes, competitivos y demandantes.

- Meta a largo plazo: logro de objetivos mayores, buena posición y penetración en el mercado, ser líder.

Fuente: Gálvez y García (2011) 


\section{Contingencia de la cultura organizacional}

Este enfoque se enfatiza en el carácter situacional y cambios del entorno que se presentan dentro de los países así mismo estos patrones culturales son tomados como modelos para las personases decir el modelo son las características de definen los valores, creencias, artefactos y supuestos básicos. Reconociendo la diversidad cultural y necesidad de laborar y actuar dependiendo de ella (Vargas, 2007). La cultura dentro de la empresa define los valores organizacionales que los miembros de una organización deben seguir, el tipo de comportamiento, que deben, la comunicación que deben manejar, la forma en que se deben expresar y la forma de hacer las cosas dentro de la organización.

Con la llegada de la globalización la cultura organizacional tiende a variar significativamente, la manera como se ejecutan los procesos dentro de una organización, hasta la forma de comunicación cambian, ya que con la inserción de nuevos patrones culturales las personas deben empezar a reaprender la manera como se realizan los procesos dentro de la misma, el trato entre colegas y los directivos empresariales, así como los protocolos de manejo e información de funciones y actividades dentro de la organización.

\section{Elementos de la cultura organizacional}

La cultura organizacional como identidad de cada organización puede desglosarse en niveles más puntuales, Schein (2010) propone tres niveles en donde la cultura hace presencia, los artefactos, los valores adoptados y los supuestos básicos, a lo que Alles (2013) afirma que la base de toda cultura organizacional está en los valores y creencias compartidos por los colaboradores de la organización. Los artefactos que constituyen el conjunto de los aspectos tangibles más susceptibles a los sentidos humanos, son denominados como el primer estrato de la cultura organizacional, se caracterizan por brindar a los miembros externos una primera impresión sobre el núcleo central de la cultura organizacional (Finch, Freeman y Gilbert, 1996), agregado a ello los artefactos también incluyen elementos tales como el comportamiento de los integrantes, la estructuración interna/externa y aquellos procesos organizacionales visibles (Zalpa, 2002).

Los valores adoptados representan el segundo estrato de la cultura y los diversos presupuestos axiológicos, éticos y morales que sirven de lineamiento a los integrantes de la organización para desarrollar los procesos de una organización de una forma u otra, los valores también se posicionan como el punto de referencia que justifican la manera de actuar de las personas (Finch, Freeman y Gilbert, 1996).

Los supuestos básicos constituyen el tercer estrato de los niveles de la cultura, son compuestos por el conglomerado de creencias y presupuestos cognitivos que se anidan en el interior de la organización (Finch, 
Freeman y Gilbert, 1996), la principal diferencia que radica entre los valores adoptados y los supuestos básicos, es que los primeros permiten prever lo que las personas dirán en determinadas circunstancias, pero realmente no propician la posibilidad de predecir su manera de actuar en dichas circunstancias (Zalpa, 2002).

\section{Dimensiones de la cultura organizacional}

La cultura organizacional si bien ha sido foco de estudio a lo largo del tiempo, abordar la temática en ocasiones resulta ambiguo y complejo, las investigaciones desarrolladas en torno a la temática buscan esclarecer concepciones conceptuales, metodológicas y genéricas, sin embargo, debido a la propia naturaleza del ser humano y la diversidad de enfoques científicos, propicia resultados diferentes, especialmente en los aspectos que giran en torno a las dimensiones y componentes de la cultura organizacional (Toca y Carrillo, 2009).El papel de la cultura en la sociedad está compuesto por una amplia gama de elementos y componentes, es por ello que existe un modelo fundamentado en una clasificación por capas (Schein, 1988; Lundberg, 2000), que representan diferentes dimensiones de la cultura; bajo esta directriz, Druckman, Singer y Van Cott (1997) también han desarrollado el concepto de clasificación de dichas capas, en una capa externa que integra todo los componentes observables de la cultura y una capa interna que incluyen los aspectos invisibles o idealizados al interior de la organización; a lo que se categorizan tres dimensiones: esencial, estratégica y manifiesta.

La dimensión esencial reúne los antecedentes e ideas que impactan los pensamientos y gestión de las organizaciones. Es la capa interna, conformada por cuatro componentes: los valores, los supuestos, las ideologías y el conocimiento. Los valores son aquellas ideas generales compartidas por la organización y que definen lo correcto desde la mirada común. Los supuestos van más allá e incluyen los sentimientos y preceptos comunes en la mayoría de los miembros de la organización en variables como tiempo, concepto de mundo y relaciones interpersonales. Las ideologías responden a las creencias generales y al compartir espiritual sobre la realidad social y las interpretaciones del día a día. Por último, está el conocimiento retratado como la evidencia conceptual de valores, juicios, explicación de situaciones, representaciones y manifiestos de la realidad, etc. El conocimiento pone en evidencia la capacidad de las personas de asimilar los hechos y emitir su interpretación de los fenómenos teniendo en cuenta su accesibilidad a los datos e información necesaria y de procesos de aprendizaje que conforman su marco cognitivo (Toca y Carrillo, 2009).

Normalmente el término estrategia está asociado a una visión de largo plazo o al nivel organizacional relacionado con el direccionamiento de la empresa concibiéndola como un todo, la dimensión estratégica de la cultura de una organización se alinea con el conjunto de convicciones y creencias de sus líderes, bus- 
cando elementos de poder para la toma de decisiones en la organización. La dimensión estratégica entonces, evoca no sólo parte de la esencia cultural sino también la parte más ajena y superflua (Toca y Carrillo, 2009).

En la dimensión manifiestalos rasgos son visibles y sus miembros identifican los inconvenientes y desaciertos de manera similar dentro de la organización. Este nivel incluye el knowhow, es decir toda la dinámica tácita de la empresa, su simbología, elementos del lenguaje y todo el comportamiento organizacional común para sus miembros (Toca y Carrillo, 2009).

\section{DISCUSIÓN}

A la luz de los resultados de la revisión, se determina que la valoración por diferentes referentes acerca de las organizaciones, como sistemas configurados coherentemente que incorporan en su estructura un conjunto de personas con una cultura adscrita que engloba tradiciones, costumbres y propiedades; así mismo es determinante del sistema de creencias que orienta la conducta y el comportamiento organizacional.

La cultura en el contexto social y antropológico representa una parte fundamental del ser, así mismo, esta incorpora un conjunto de dimensiones y niveles de análisis que coadyuvan a identificar el comportamiento de las personas en comunidad, comprender la cultura en su estricto sentido requiere la eliminación de ciertos supuestos y paradigmas que en ocasiones relacionan el concepto con los modales o practicas moralmente aceptadas; pues su mayor relación radica en la influencia del sistema de creencias de las personas y como ciertos principios inciden en la conducta social.

La concepción de cultura se extrapola al ámbito de las organizaciones mediante lanoción de cultura organizacional, que representa un código único que fortifica la identidad corporativa, el sentido de pertenencia y funciona de engrane entre los diferentes niveles de la estructura orgánica, así mismo, esto significa para la gerencia un factor de gran relevancia que puede ser gestionado para la creación de valor y mejorar los resultados.

Complementario a ello, también se desglosa a la cultura organizacional en diferentes niveles y elementos que se pueden categorizar como tácitos o explícitos, en este sentido se debe tener en cuenta que en diferentes escenarios se puede ubicar la cultura como un generador de capital relacional al incidir en las relaciones laborales de los colaboradores.

La comprensión del marco histórico que envuelve a las organizaciones, indica que siempre ha sido la- 
tente para el ser humano la necesidad de organizarse para logar sus objetivos y la convivencia en sociedad ha marcado la cultura de cada comunidad, etnia o nación, elemento que es clave para la determinación de costumbre, conducta, tradición y entre otros aspectos como: el lenguaje, religión y estilos de vida; y al igual que las sociedades, las organizaciones cuentan con una cultura propia que se origina de la convivencia de sus colaboradores.

Puede afirmarse que a diferencia de la cultura de las sociedades, la cual normalmente es adquirida por los individuos y de alguna manera estática, la cultura organizacional por el contrario es construida entre colaboradores de las organizaciones y al ser las personas cambiantes, esta tiende a ser dinámica, pero conservando la esencia de la forma organizacional respectiva.

La relevancia de la cultura para las organizaciones radica en que esta representa un sistema configurado de creencias y valores compartidos que modelan la conducta, el comportamiento y la disposición de los colaboradores a procesos que los directivos de organizaciones enfrentan día a día tales como: liderar equipos de trabajo, gestionar procesos de cambio e incluso mantener la sana convivencia en la organización; entonces siempre será la cultura de las organizaciones una relevante variable y aspecto a conocer para la gestión organizacional.

\section{REFERENCIAS}

Abreu, J. L. (2012). Hipótesis, método y diseño de investigación. International Journal of Good Conscience 7(2). 187-197

Aguirre, J. y Jaramillo, L. (2015). El papel de la descripción en la investigación cualitativa. Cinta de Moebio. (53) 175-189.

Allaire, Y. y Firsirotu, M. (1984). Theories of organizational culture. Organization Studies. 5(3), 193-226.

Alles, M. (2013). Comportamiento organizacional: Cómo lograr un cambio cultural a través de gestión por competencias. Buenos Aires: Ediciones Granica.

Alonso, E., Ocegueda, V. y Castro, E. (2006). Teoría de las organizaciones. Zapopan: Editorial Umbral.

Atehortúa, F., Bustamante, R. y Valencia, J. (2008). Sistemas de gestión integral: Una sola gestión, un solo equipo. Colombia: Editorial Universidad de Antioquia.

Barney, J. B. (1991). Firm resources and sustained competitive advantage. Journal of Management 17(1), 99-120.

Berger, B. (1991). The culture of modern entrepreneurship. San Francisco: ICS Press.

Bertalanffy, L. V. (2006). Teoría general de los sistemas: fundamentos, desarrollo y aplicaciones. México: Fondo de Cultura Económica. 
Bourdieu, P. (1979). Les troisétats du capital culturel. Actes de la recherche en sciences sociales.30(30), 3-6.

Cameron, K. y Quinn, R. (2011). Diagnosing and changing organizational culture. USA: Jossey-Bass.

Contreras, R., López, A. y Ríos, M. (2011). Cultura empresarial: Análisis social de los valores en la MiPyme. México: Universidad de Guanajuato.

Cuervo, G. (1993). El papel de la empresa en la competitividad. Papeles de Economía Española (56), 363377.

Da Silva, L., Kishore, A., Germano, G., Lopes, L. y Medeiros, C. (2013). Cultura organizacional e liderança: umarelaçãopossível? Revista de Administração48(1), 34-52.

David, F. (2003). Conceptos de administración estratégica. (9a ed.). México: Pearson Educación.

Davis, K. (1993). Comportamiento humano en el trabajo. México: McGraw-Hill

De la Hoz, R. y Forero, G. (2013). Ambientes educativos dinamizadores de energía creativa e innovadora. Barranquilla: Editorial Universidad del Atlántico

Donaldson, T. (1996). Values in tension: ethics away from home. Harvard Business Review, 48-62.

Druckman, D., Singer, J. y Van Cott, H. (1997). Enhancing organizational performance. Washington D.C.: National Academy Press.

Elton Mayo, G. (2004). The human problems of an industrial civilization.New York: Routledge

Estrada, R. y Sánchez, V. (2009). Herramientas estratégicas en la Pyme y su efecto en la planeación y el rendimiento: una evidencia empírica. Revista de Economía 26(73), 71-87.

Finch, J., Freeman, E. y Gilbert, D. (1996). Management. Virginia: Prentice Hall.

Fleury, J. (2002). La culture. Paris: Bréal.

Gabriel, S. y Gardner, W. (1999). Are there "his" and "hers" types of interdependence? The implications of gender differences in collective versus relational interdependence for affect, behavior, and cognition. USA, J. Pers. Soc. Psychol.

Gálvez, E. y García, D. (2011). Cultura organizacional y rendimiento de las miPymes de mediana y alta tecnología: un estudio empírico en Cali, Colombia. Cuadernos de administración. 24(42), 125-145.

Gerschenkron, A. (1974). Atraso económico e industrialización. Barcelona: Ariel.

Herrera, C., Inglehart, R., Baker, W. y García, N. (2002). El capital cultural y su impacto en el desarrollo. Texas: Centro cultural del BID.

Hirschman, A. (1958). The strategy of economic development. New Haven: Yale University Press.

Hofstede, G. (1980). Culture's Consequences: International Differences in Work-Related Values. Beverly Hills: SagePublications.

Jiménez, I. (1997). Prólogo. En Bourdieu, P. Capital cultural, escuela y espacio social. México: Siglo XXI. Kilman, R., Saxton, M. y Serpa, R. (1985). Gaining control of corporate culture.USA: Jossey-Bass.

Kotter, J. y Heskett, J. (1995). Cultura de empresa y rentabilidad. Madrid: Ediciones Díaz de Santos. 
Laplantine, F. (1993). Clefs pour l'anthropologie. Paris: Seghers.

Lessem, R. (1992). Gestión de la cultura corporativa. Madrid: Díaz de santos.

Lundberg, C. (2000). Knowing and surfacing organizational culture. A consultant's guide. New York: Marcel Dekker Inc.

Maas, M. (2006). Gestión cultural, comunicación y desarrollo: teoría y práctica.México: UNAM

McGregor, D. (2006). The human side of entreprise, annotated edition. New York: McGraw-Hill.

Méndez, C. (2006). Clima organizacional en Colombia: el IMCOC: un método de análisis para su intervención. Bogotá: Universidad del Rosario.

Mendoza, J. M. (2013). La capacidad dinámica de ripostar en la empresa: confrontar entornos volátiles. Cuadernos de Administración 26(47). 63-85.

Mintzberg, H. (1988). La estructuración de las organizaciones. España: Ariel economía.

Mintzberg, H. (2010). Managing. Bogotá: Ed. Norma.

Montaño, L. (2000). La dimensión cultural de la organización. Elementos para un debate en América Latina (pp. 285-311). En E. De la Garza (Coordinador). Tratado latinoamericano de sociología del trabajo. México: COLMEX, FLACSO, UAM, FCE

Morcillo, P. (2007). Cultura e innovación empresarial: la conexión perfecta. España: Thomson.

Morgan, G. (1997). Images of organizations. New Delhi: Sage Publications.

Morín, E. (1999). Los siete saberes necesarios para la educación del futuro. Francia: Santillana.

Mouzelis, N. (1973). Organización y burocracia. (3a ed.). Barcelona: Ediciones 62.

North, D. (1990). Institutions, institutional change, and economic performance. USA: Cambridge UniversityPress.

Rojas, I. (2011). Elementos para el diseño de técnicas de investigación: una propuesta de definiciones y procedimientos en la investigación científica. Tiempo de educar 12(24) 277-297.

Ruiz, Y. y Naranjo, J. (2012). La investigación sobre cultura organizacional en Colombia: Una mirada desde la difusión de las revistas científicas. Divers: Perspectiva psicológica. 8(2), 285-307.

Schein, E. (1988). La cultura empresarial y el liderazgo. España: Plaza \& Janes.

Schein, E. (2010). Organizational culture and leadership. San Francisco: Jossey Bass.

Simon, H. (2013). Administrative Behavior. (4a ed.). New York: The Free Press.

Smircich, L. (1983). Concepts of culture and organizational analysis. AdministrativeScienceQuarterly.28(3), 339-358

Toca, C. y Carrillo, J. (2009). Aspectos teóricos y metodológicos de la cultura organizacional. Civili$\operatorname{zar} 9(17), 117-136$.

Triandis, H. (2004) The many dimensions of culture. Academy of Management Executive. (18)1, 88-93.

Triandis, H. y Suh, E. (2002) Cultural influences on personality. Annualreview of psychology. (53), 133-160 
Uribe, R. (2007). Estructura y cultura organizacional en la Pyme Colombiana: Análisis en Empresas Bogotanas. Cuadernos de Administración. (38), 73-85.

Vargas, J. (2007). La culturocracia organizacional en México. México: Juan Carlos Martínez Coll.

Wallace, A. (1970). Culture and personality. New York: Random House.

Zalpa, G. (2002). La cultura en las organizaciones empresariales. Estudios sobre las culturas contemporáneas. 8(15), 9-33.

Zapata, A. y Rodríguez, A. (2008). Gestión de la cultura organizacional: bases conceptuales para su implementación. Cali: Universidad del Valle. 